\title{
Parasite co-infections show synergistic and antagonistic interactions on growth performance of East African zebu cattle under one year
}

\author{
S. M. THUMBI ${ }^{1}$ ** $\uparrow$, B. M. de. C. BRONSVOORT ${ }^{2}$, E. J. POOLE ${ }^{3}$, H. KIARA ${ }^{3}$, P. TOYE ${ }^{3}$, \\ M. NDILA ${ }^{3}$, I. CONRADIE ${ }^{4}$, A. JENNINGS ${ }^{2}$, I. G. HANDEL ${ }^{2}$, J. A. W. COETZER ${ }^{4}$, \\ O. HANOTTE ${ }^{5}$ and M. E. J. WOOLHOUSE ${ }^{1}$ \\ ${ }^{1}$ Centre for Infectious Diseases, University of Edinburgh, Ashworth Laboratories, Kings Buildings, West Mains Road, \\ Edinburgh EH9 $3 \mathcal{Y T}$, UK \\ ${ }^{2}$ The Roslin Institute, Easter Bush, University of Edinburgh, Roslin, Midlothian EH25 9RG, UK \\ ${ }^{3}$ International Livestock Research Institute, P.O. Box 30709, Nairobi 00100, Kenya \\ ${ }^{4}$ Department of Veterinary Tropical Diseases, Faculty of Veterinary Science, University of Pretoria, Private bag X04, \\ Onderstepoort, South Africa \\ ${ }^{5}$ School of Life Science, University of Nottingham, University Park, Nottingham NG7 2RD, UK
}

(Received 6 April 2013; revised 23 May 2013; accepted 9 Fune 2013; first published online 4 September 2013)

\section{SUMMARY}

The co-occurrence of different pathogen species and their simultaneous infection of hosts are common, and may affect host health outcomes. Co-infecting pathogens may interact synergistically (harming the host more) or antagonistically (harming the host less) compared with single infections. Here we have tested associations of infections and their co-infections with variation in growth rate using a subset of 455 animals of the Infectious Diseases of East Africa Livestock (IDEAL) cohort study surviving to one year. Data on live body weight, infections with helminth parasites and haemoparasites were collected every 5 weeks during the first year of life. Growth of zebu cattle during the first year of life was best described by a linear growth function. A large variation in daily weight gain with a range of $0 \cdot 03-0 \cdot 34 \mathrm{~kg}$, and a mean of $0 \cdot 135 \mathrm{~kg}(0 \cdot 124,0 \cdot 146$; 95\% CI) was observed. After controlling for other significant covariates in mixed effects statistical models, the results revealed synergistic interactions (lower growth rates) with Theileria parva and Anaplasma marginale co-infections, and antagonistic interactions (relatively higher growth rates) with $T$. parva and Theileria mutans co-infections, compared with infections with T. parva only. Additionally, helminth infections can have a strong negative effect on the growth rates but this is burden-dependent, accounting for up to $30 \%$ decrease in growth rate in heavily infected animals. These findings present evidence of pathogen-pathogen interactions affecting host growth, and we discuss possible mechanisms that may explain observed directions of interactions as well as possible modifications to disease control strategies when co-infections are present.

Key words: co-infections, interactions, growth rate, cattle.

\section{INTRODUCTION}

Events that occur early in a host's life, including infection with pathogens, are important determinants of the reproductive and production success of individuals. Parasite infections cause significant losses through loss of body condition, inefficiency of food utilization, for example in helminth infections, decreased reproductive fitness or deaths, and are a major threat to success of infected individuals. Infections in natural populations are known to involve multiple pathogens rarely occurring as single

* Corresponding author: Centre for Infectious Diseases, University of Edinburgh, Ashworth Laboratories, Kings Buildings, West Mains Road, Edinburgh EH9 3JT, UK. E-mail: samthumbi@gmail.com

$\uparrow$ Current addresses: Paul G. Allen School for Global Animal Health, Washington State University, Pullman, WA 99164-7079 USA and KEMRI/CDC Research and Public Health Collaboration, P.O. BOX 1578, Kisumu 40100, Kenya. infections (Boag et al. 2001; Cox, 2001; Lello and Hussell, 2008). Despite this, little is known about the consequences of harbouring co-infections on important traits such as growth rates, and whether there are pathogen-pathogen interactions that should be considered in programmes aimed at disease control.

Within a host, the co-infecting pathogens may not always act independently of each other, and may interact, modifying the densities of each other and their impact on the infected host as opposed to when they exist as single infections (Craig et al. 2008; Telfer et al. 2010). Various mechanisms for these interactions have been suggested including community ecology theories as competitive interactions between pathogens sharing similar resources or location in a host (Pedersen and Fenton, 2007; Graham, 2008) or interactions with host immune system where new parasites infecting a host find an immuno-environment created in response to previous 
or current infections (Lafferty, 2010; Telfer et al. 2010). Such interactions complicate current diseaseby-disease impact studies and accurate estimates of disease burden would need to account for the impact that parasite-parasite and parasite-host interactions have on host outcomes (Fenton and Perkins, 2010).

Here we study co-infections and their impact on East African zebu cattle, which are raised in smallholder production systems under low veterinary input for disease control and treatment. The environment they are raised in is endemic for a range of micro- and macro-parasites, and provides a good system to study co-infections and increase our understanding of parasite interactions and their impact on host outcomes. Zebu cattle are an important source of livelihood for a large rural population in sub-Saharan Africa, and their improved production present opportunities for improving the livelihoods of these livestock keepers (Perry, 2002, 2007; Kristjanson et al. 2004; 'Tarawali et al. 2011). Despite zebus' relative resistance and resilience compared with European breeds (Ndungu et al. 2005), livestock diseases in zebu cattle remain a major constraint causing mortalities and sub-optimal production, and their control is seen as an important step towards improved production and better livelihoods (Perry, 2002, 2007; Tomley and Shirley, 2009).

By following a cohort of indigenous zebu cattle raised in disease-endemic areas in Western Kenya, here we study the weight-age relationship from birth to one year. Specifically, we investigate: (a) the impact of non-infectious factors on the growth rate, and controlling for these non-infectious factors; (b) the effect of individual infections on growth rate of calves less than one year; and (c) the impact of different co-infection profiles on growth rates. This study seeks to evaluate the costs of an animal surviving parasitic infections by determining the differential impact that infections, co-infections and their interactions have on the outcome 'growth rate'. Knowledge of environmental factors, infections and co-infection profiles with the greatest impact on growth rates should be an integral part of design programmes aimed at disease control, including improved livestock production.

MATERIALS AND METHODS

\section{Data collected}

Between October 2007 and September 2010, a total of 548 East African zebu calves were recruited into the Infectious Diseases of East African Livestock (IDEAL) cohort study at birth and followed during their first year of life. The animals came from 20 sub-locations (smallest administrative units) falling within four agro-ecological zones in Western Kenya. Each study animal was routinely monitored every 5 weeks from birth until one year or earlier if lost from the study. During the follow-up period, routine clinical examinations on study calves were conducted every 5 weeks, and blood, fecal and other clinically relevant samples collected, stored and later processed for laboratory diagnosis. Data on farm management practices, herd health and veterinary interventions on the herd during the inter-visit period were collected. Live body weight $(\mathrm{kg})$ and girth measurements $(\mathrm{cm})$ were recorded at recruitment, and every 5 weeks thereafter until 31 weeks old. A final body weight and girth measurement was taken at 51 weeks before animals left the study. Additionally, maternal data including the dam's general health, udder health, girth measurements and body condition score were recorded during each corresponding calf visit, until weaning or the calf left the study. Detailed description of the study design and protocol are provided by Bronsvoort et al. (in press). In this study we use data on a subset of 455 calves of the IDEAL cohort that completed a full year of observation. The study received approval by the University of Edinburgh Ethics Committee (reference number OS 03-06), and the Animal Care and Use Committee of the International Livestock Research Institute. All participating farmers gave informed consent in their native language before recruiting their animals into the study.

\section{Predictor variables}

Variables that were tested for their association with growth of calves during the first year of life included: (a) Farmer-related factors: including farmer's education level, main occupation, gender and age, as well as herd and land sizes owned; (b) management factors: including livestock housing, disease, feeding and watering, and disease control practices within the farm; (c) calf factors: calf sex, level of European taurine introgression and heterozygosity; (d) environmental factors: elevation, Normalized Difference Vegetation Index (NDVI); and (e) dam factors: body condition scores, heart girth measurements, general health and udder health.

\section{Infection data}

Fecal, blood and other clinically relevant samples such as skin scrapings and bacterial swabs collected during the monitoring visits were processed and screened for a range of micro- and macro-parasites. The pathogens screened for and diagnostic methods used are provided in Table 1.

\section{Data analysis}

Analysis of growth curves and factors associated with growth rate were carried out using mixed-effects models, which can account for both temporal and spatial correlation in the data. By accounting for the sequential structure in the fixed and random 


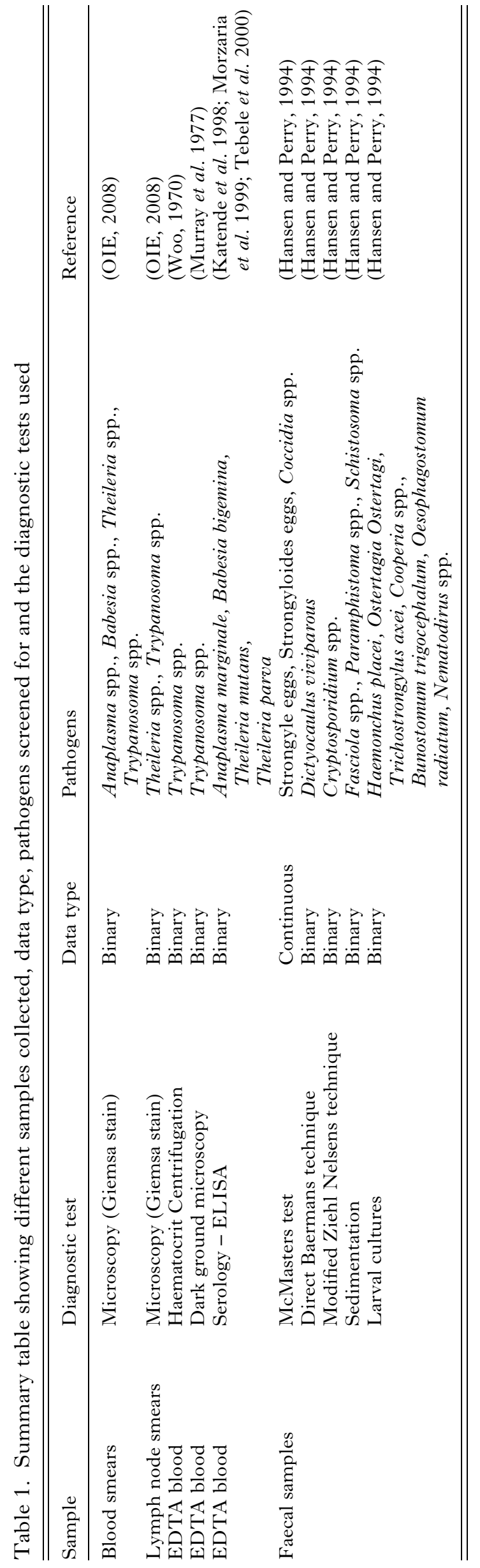

effects and in the correlation structure, it is possible to include time-varying predictors such as infection status directly in the analysis. Their effect is modelled against their occurrence time, enabling insights that would otherwise not be seen by ignoring the sequential structure (Willett, 1997; Gröhn et al. 1999). Here, we investigate how the live weight changes with age, and how infection and non-infection factors shape these growth curves. The model used in the analysis is presented in equation (1).

$$
\begin{gathered}
Y_{i j}=\alpha_{00}+\alpha_{10} \mathrm{Age}_{i j}+\alpha_{01} \text { Predictor }_{i}+\alpha_{11} \\
\left(\text { Predictor }_{i} \times \operatorname{Age}_{i j}\right)+\zeta_{0 i}-\zeta_{I i} \text { Age }_{i j}+\varepsilon_{i j}
\end{gathered}
$$

The equation has a structural part and an error part. It models the live body weight of calf $i$ at time $j\left(Y_{i j}\right)$. Using a categorical predictor variable (calf sex) for illustration, the structural part of equation (1) estimates four main parameters of interest corresponding to the fixed effects:

(a) $\alpha_{00}$ : Estimated initial weight of male calf in the population, which is the reference category the reference intercept.

(b) $\alpha_{01}$ : Estimated differential in the initial weight for female calves - the adjusted intercept value for female calves.

(c) $\alpha_{10}$ : Estimated rate of growth in male calves - the reference slope.

(d) $\alpha_{11}$ : Estimated differential rate of growth in female calves - the adjusted slope value for female calves.

The statistical significance of these estimated parameters is evaluated to determine if there are significant differences between the starting weights and growth rates among male and female calves. In case the predictor variable is continuous, $\alpha_{00}$ would be the estimated initial weight value when the predictor variable $y$ is zero, and $\alpha_{11}$ would be the differential rate in growth for every unit increase in the level of the predictor variable $Y$. The estimates at time $0(j=0)$ may not be interpreted in certain instances dependent on the variable under study (such as estimate of effect of infection at birth when it cannot occur), but generally this does not affect model estimates for the slopes. The continuous variables can be 'centred' on their means (by subtracting a constant e.g. the mean value from the predictor before running the model) to facilitate interpretation.

The error part in the composite model equation (1) captures the three sources of random variation in longitudinal studies (Diggle et al. 2003):

(a) Random effects: $\left(\zeta_{0 i}\right)$ Each study subject has intrinsic characteristics different from those of other subjects in the study, giving each individual a specific response profile. These are incorporated in the models by introducing study 
subjects as random effects, and modelling the within-individual variation.

(b) Serial correlation: $\left(\zeta_{1 i} \mathrm{Age}_{i j}\right)$ Weights recorded from the same individual over time may be correlated, with the correlation between a pair of measurements decreasing with increase in separation time. A number of correlation structures for the repeated measures are considered, and the structure closest to the actual relationship (with the largest log-likelihood among competing models) is selected for use as the base unconditional growth model.

(c) Measurement error: $\left(\varepsilon_{i j}\right)$ The measurement process as taking of live body weights adds variation in the data.

Univariable screening of the putative variables was carried out, and variables with a $P$-value $\leqslant 0 \cdot 2$ offered to the multivariable analysis. Following univariable analysis, interactions between biologically plausible non-infectious factors and infectious factors were tested. Backward elimination was carried out through sequentially removing terms from the maximum model starting with interaction terms and variables with least significant $P$-values. This analysis proceeded in two steps; first with identification of noninfectious factors associated with growth rate, and secondly, while controlling for significant noninfectious factors, determined the relationship between infectious factors and growth rate. Interaction terms were allowed in the final model only if their main effects were significant. The final model contained only significant terms of $P$-value $<0 \cdot 05$. The terms were then individually added back and model comparisons made to determine if the terms significantly improved the model fit.

To account for the spatial correlation arising from the 2-stage cluster study design and sampling, sublocation was included as a random effect in the final model. The repeated measures analysis was carried out using nlme statistical package (Pinheiro and Bates, 2000), on the R platform (R Development Core Team, 2011). This allows for specification of the correlation structure, and random effects structure. The model in $\mathrm{R}$ was coded as follows:

$$
\begin{aligned}
& \text { Model }<- \text { lme }(\text { LiveWeight } \sim \text { CalfAge }+ \text { predictors, } \\
& \text { random }=(\sim \text { CalfAge } \mid \text { CalfID }), \text { corARMA }(\mathrm{q}=4))
\end{aligned}
$$

where age of calf (CalfAge) and predictors (e.g. calf sex, infection status etc.) are the fixed effects. Each calf (CalfID) was fitted as a random effect to account for the correlation between measurements taken from the same calf over observation time. An autoregressive-moving average (corARMA) to account for correlations consecutive measurements from the same individual was used. The model diagnostics to check whether distributional assumptions were violated was done by visual inspection of residuals, fitted values and the estimated random effects (Pinheiro and Bates, 2000).

RESULTS

\section{Outcome measure}

The mean daily weight gain (growth rate) was estimated at $0 \cdot 134 \mathrm{~kg}(0 \cdot 124,0 \cdot 146 ; 95 \% \mathrm{CI})$. The mean live body weight at recruitment was $19 \cdot 2 \mathrm{~kg} \pm 3 \cdot 7 \mathrm{SD}$ (range 8-29.5), and at one year $65 \cdot 2 \mathrm{~kg} \pm 17 \cdot 72 \mathrm{SD}$ (range 29-144). A large variation in growth rates of up to 10 -fold difference (minimum $0.03 \mathrm{~kg}$ and maximum $0.34 \mathrm{~kg}$ daily weight gain) was observed. The percentage body weight gain over one year ranged from as low as $50 \%$ to as high as over $700 \%$. Variation in live body weight increased with age (see Fig. 1).

\section{Mixed-effect models}

The selection of the growth function to adopt for analysis of factors affecting growth was based on a formal examination of model fit using different growth functions, examination of graphical growth trajectories, and the ease of interpretation of the growth parameters from the models. Based on these criteria, a linear growth model with a varying slope and intercept and assuming a moving average correlation structure was selected as the unconditional growth model. Adding sub-location as a random effect did not significantly improve the model fit. The comparison between the linear models is presented in Supplementary Table 1S - in Online version only. This was subsequently used in the analysis of infectious and non-infectious factors associated with growth rates in zebu calves.

Results from univariable analysis testing the association between infectious and non-infectious factors showing variables with a $P$-value $<0 \cdot 2$ and offered to the multivariable analysis are presented in Supplementary Tables 2 and $3 \mathrm{~S}-$ in Online version only. After model simplification, the final model estimated growth rate at $134.7 \mathrm{~g} \mathrm{day}^{-1}$ (equivalent to $49 \cdot 2 \mathrm{~kg}$ weight gain in a year), see results of final model in Table 2.

Calves from farms where the farmer had a salaried income had higher growth rates, gaining $8.3 \mathrm{~kg}$ more in a year compared with farms where the farmer was not salaried. Female calves gained $4.7 \mathrm{~kg}$ less compared with male calves in a year. Large heart girth size in the dams was associated with higher growth rates, with a $10 \mathrm{~cm}$ deviation from the mean girth of the population associated with $5.8 \mathrm{~kg}$ higher gain in a year from the average. An increase in the altitude of the farm by $100 \mathrm{~m}$ was associated with a $4 \cdot 2 \mathrm{~kg}$ higher gain in weight in a year.

Controlling for the effects of non-infectious factors, infections with helminths (strongyle EPG 


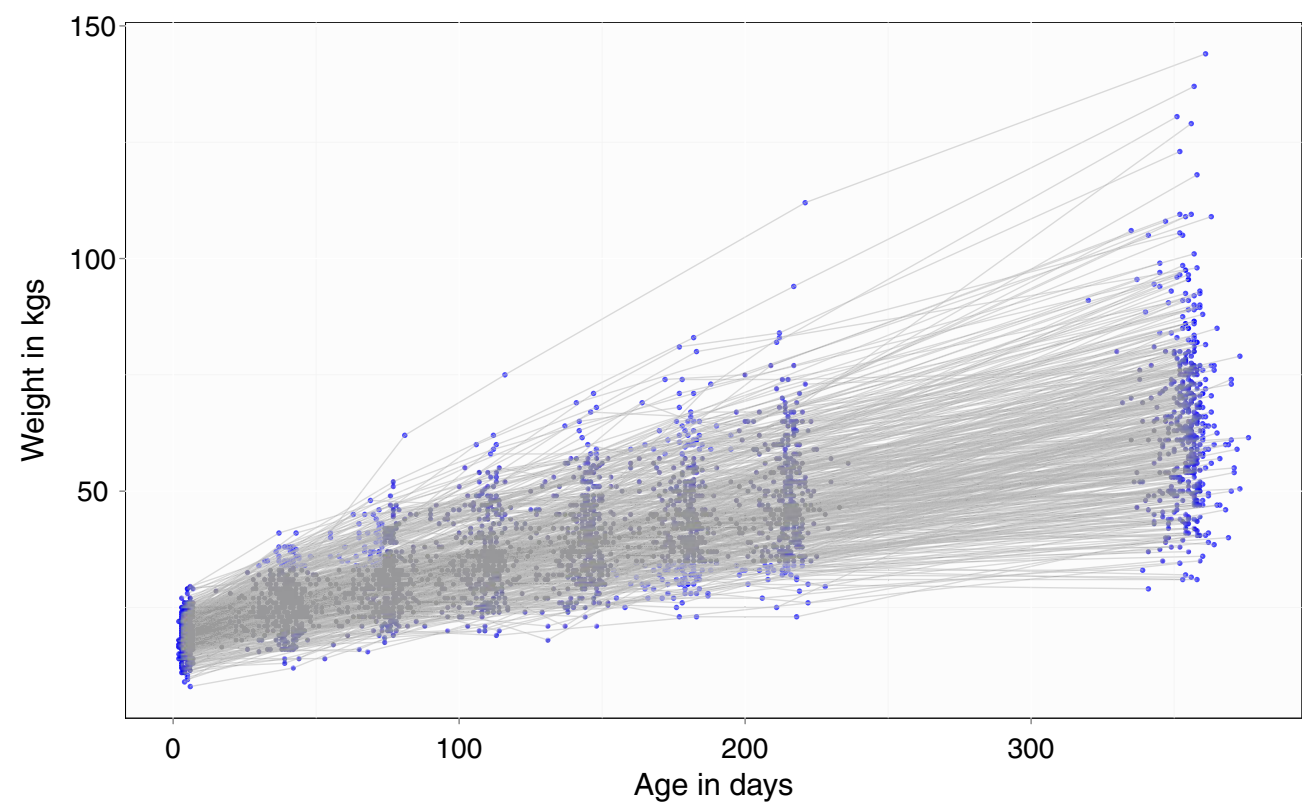

Fig. 1. Growth trajectories of the 455 calves that completed the one year observation time. The blue dots are individual's weights recorded and the grey lines connect repeated measures for each calf. Routine weight measurements were done from birth up to week 31 of age, and thereafter at the final visit done at week 51 before leaving the study.

count), with fungi Trichophyton spp., and with Theileria parva seropositive had a significant negative association with growth rate. Additionally, there was evidence of co-infection interactions differing in size and direction; antagonistic interactions between T. parva and Theileria mutans, and synergistic interactions between $T$. parva and Anaplasma marginale.

Calves that had experienced seropositivity for $T$. parva were estimated to gain $6.7 \mathrm{~kg}$ less on average compared with animals that did not sero-convert during the one-year observation time. This is the equivalent of $13 \cdot 7 \%$ decrease in average growth rate associated with $T$. parva seropositivity. The model estimate for the effect of infection with $A$. marginale, while controlling for all other significant predictors, was a marginal decrease in growth $(0.7 \mathrm{~kg}$ difference in weight gained over one year compared with uninfected animals). However, animals co-infected with $T$. parva and $A$. marginale had an estimated growth rate lower than the combined negative effects of each infection, a synergistic interaction. Calves coinfected with the two were estimated to have gained $11.6 \mathrm{~kg}$ less in one year compared with uninfected animals, equivalent to $23 \cdot 6 \%$ less than the average growth rates for uninfected animals.

Co-infections between T. parva and T. mutans were antagonistic with the effect on growth rates of the more pathogenic T. parva infections moderated in the presence of T. mutans. Whereas the weight gain of $T$. parva seropositive calves was estimated to reduce by $6.7 \mathrm{~kg}$ over a year, animals seropositive for both $T$. parva and T. mutans were estimated to have a weight gain only $3.3 \mathrm{~kg}$ less that of uninfected animals. This is equivalent to a $6 \cdot 7 \%$ decrease in average growth rate associated with $T$. parvaT. mutans co-infections, approximately half $(13 \cdot 7 \%)$ that estimated for a $T$. parva-only infection.

High worm burden was associated with decreased growth rates. An increase in strongyle epg by a count of 1000 eggs was associated with a $1 \cdot 6 \mathrm{~kg}(3 \cdot 3 \%)$ lower gain in the year. Infection with Trichophyton spp. was associated with reduced weight gain estimated at $9.3 \mathrm{~kg}(18.9 \%)$ less than the average weight gain in a year. A schematic diagram (Fig. 2) shows the relationship between the daily weight gain (slope in the models) and the significant factors associated with growth rates.

The intra-class correlation (ICC) coefficient was used to determine the fraction of the total residual variation that was accounted for by differences between calves (Weir, 2005). The calculated ICC was 0.79 indicating $79 \%$ of the residual variation in growth rates was accounted for by between-calf differences, the remaining being error.

\section{DISCUSSION}

This study has investigated factors that determine growth rates in zebu cattle during the first year of life, specifically assessing the impact of infections and their co-infections on growth rates. In this study growth during the first year of life was best described as a linear growth function, with an estimated growth rate of $134.7 \mathrm{~g} \mathrm{day}^{-1}$. Similar growth rates $(120 \mathrm{~g}$ day $^{-1}$ ) have been reported among zebu calves in Lake Victoria's Rusinga Island, Western Kenya (Latif et al. 1995). Although these growth rates 
Table 2. Results of minimum adequate mixed model showing the significant infectious and non-infectious factors associated with growth rate $\left(\mathrm{kg} \mathrm{day}^{-1}\right)$ in zebu calves under one year. Dam heart girth size and farm altitude (elevation) were centred around their mean values to facilitate interpretation

\begin{tabular}{|c|c|c|c|c|c|c|}
\hline Variable & Estimate & lowerCI & upperCI & $\mathrm{DF}$ & $t$-value & $P$-value \\
\hline \multicolumn{7}{|l|}{ Intercept } \\
\hline Initial weight estimate & $20 \cdot 855$ & $19 \cdot 344$ & $22 \cdot 366$ & 1055 & $27 \cdot 09$ & $<0 \cdot 001$ \\
\hline (Dam Heart girth size-135)/10 & $-0 \cdot 464$ & $-1 \cdot 403$ & $0 \cdot 474$ & 1055 & $-0 \cdot 97$ & $0 \cdot 332$ \\
\hline Occupation - salaried & $-1 \cdot 230$ & $-3 \cdot 685$ & $1 \cdot 225$ & 427 & -0.99 & $0 \cdot 325$ \\
\hline$($ Elevation - 1240)/100 & $0 \cdot 872$ & $-0 \cdot 456$ & $2 \cdot 199$ & 427 & $1 \cdot 29$ & $0 \cdot 198$ \\
\hline Watering at homestead & $0 \cdot 805$ & $-0 \cdot 801$ & $2 \cdot 412$ & 427 & $0 \cdot 99$ & $0 \cdot 325$ \\
\hline Calf sex - female & $-0 \cdot 058$ & $-1 \cdot 654$ & $1 \cdot 537$ & 427 & $-0 \cdot 07$ & $0 \cdot 943$ \\
\hline T. parva seropositive & $1 \cdot 109$ & $-0 \cdot 355$ & $2 \cdot 574$ & 1055 & $1 \cdot 49$ & $0 \cdot 137$ \\
\hline T. mutans seropositive & $-0 \cdot 339$ & $-1 \cdot 637$ & 0.958 & 1055 & $-0 \cdot 51$ & $0 \cdot 608$ \\
\hline A. marginale seropositive & $2 \cdot 409$ & $0 \cdot 248$ & $4 \cdot 571$ & 1055 & $2 \cdot 19$ & $0 \cdot 029$ \\
\hline Trichophyton spp. & $1 \cdot 096$ & $-2 \cdot 254$ & $4 \cdot 446$ & 1055 & $0 \cdot 64$ & $0 \cdot 521$ \\
\hline (Strongyle epg/1000) & $0 \cdot 287$ & $-0 \cdot 147$ & $0 \cdot 722$ & 1055 & $1 \cdot 3$ & $0 \cdot 195$ \\
\hline \multicolumn{7}{|l|}{ Growth rate (slope) } \\
\hline Age in days & $0 \cdot 134$ & $0 \cdot 124$ & $0 \cdot 146$ & 1055 & $24 \cdot 28$ & $<0 \cdot 001$ \\
\hline Age:(Dam heart girth -135$) / 10$ & $0 \cdot 016$ & $0 \cdot 010$ & $0 \cdot 021$ & 1055 & $5 \cdot 49$ & $<0 \cdot 001$ \\
\hline Age: Occupation - salaried & $0 \cdot 023$ & $0 \cdot 008$ & $0 \cdot 038$ & 1055 & $2 \cdot 94$ & $0 \cdot 003$ \\
\hline Age: $($ Elevation - 1240)/100 & $0 \cdot 012$ & $0 \cdot 003$ & $0 \cdot 020$ & 1055 & $2 \cdot 68$ & $0 \cdot 007$ \\
\hline Age: Watering at homestead & $0 \cdot 012$ & $0 \cdot 001$ & $0 \cdot 022$ & 1055 & $2 \cdot 23$ & $0 \cdot 026$ \\
\hline Age: Calf sex - female & $-0 \cdot 013$ & $-0 \cdot 023$ & $-0 \cdot 003$ & 1055 & $-2 \cdot 52$ & $0 \cdot 012$ \\
\hline Age: T. parva seropositive & $-0 \cdot 018$ & $-0 \cdot 028$ & $-0 \cdot 008$ & 1055 & $-3 \cdot 62$ & $<0 \cdot 001$ \\
\hline Age: T. mutans seropositive & $-0 \cdot 002$ & $-0 \cdot 012$ & $0 \cdot 008$ & 1055 & $-0 \cdot 41$ & 0.683 \\
\hline Age: A. marginale seropositive & $-0 \cdot 002$ & $-0 \cdot 014$ & $0 \cdot 010$ & 1055 & $-0 \cdot 33$ & $0 \cdot 741$ \\
\hline Age: Trichophyton spp. & $-0 \cdot 025$ & $-0 \cdot 047$ & $-0 \cdot 004$ & 1055 & $-2 \cdot 32$ & $0 \cdot 021$ \\
\hline Age: (Strongyle epg/1000) & $-0 \cdot 004$ & $-0 \cdot 007$ & $-0 \cdot 002$ & 1055 & $-3 \cdot 38$ & $<0 \cdot 001$ \\
\hline Age: T.parva-T. mutans & $0 \cdot 012$ & $0 \cdot 004$ & $0 \cdot 019$ & 1055 & $2 \cdot 9$ & $0 \cdot 004$ \\
\hline Age: T.parva-A. marginale & $-0 \cdot 011$ & $-0 \cdot 019$ & $-0 \cdot 003$ & 1055 & $-2 \cdot 76$ & $0 \cdot 006$ \\
\hline Intra-class correlation & $0 \cdot 79$ & & & & & \\
\hline
\end{tabular}

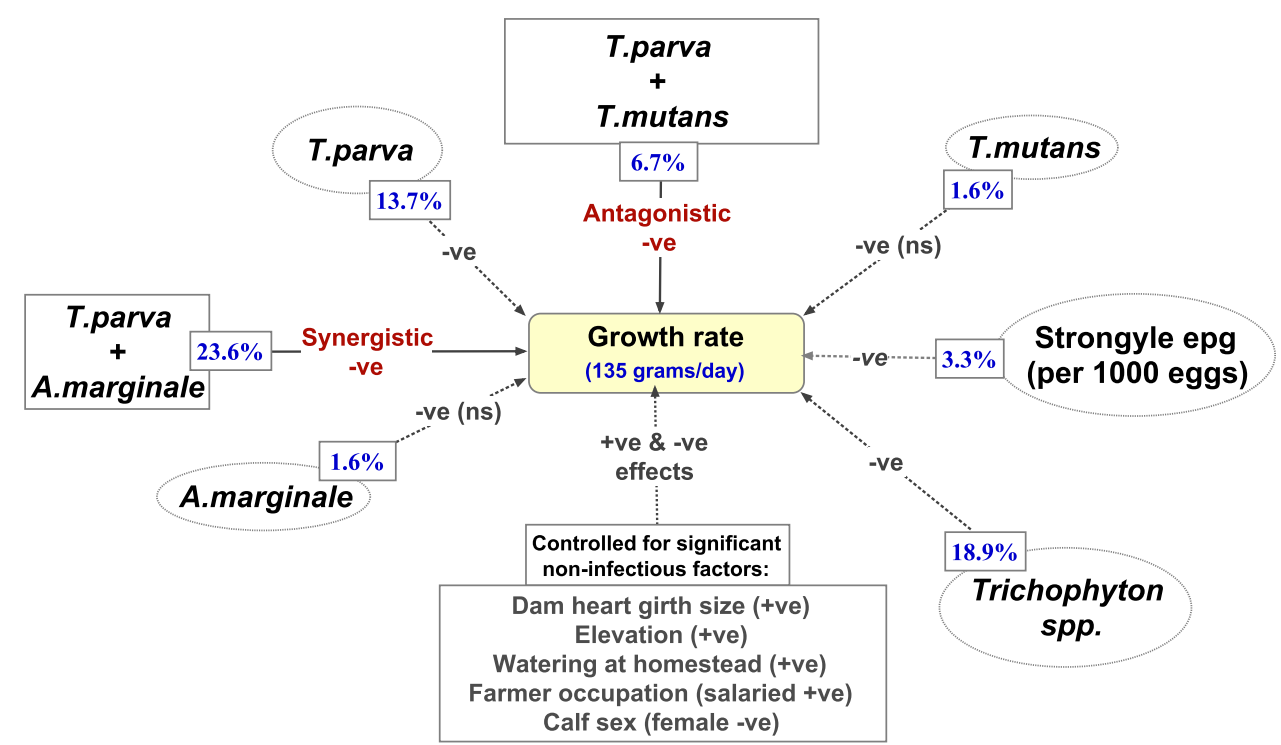

Fig. 2. Schematic diagram showing associations between average daily weight gain and different infections and co-infections. Negative associations with ADWG have the sign $(-v e)$, and positive $(+v e)$. All single infections have a negative effect on ADWG. The size of the effect expressed as a percentage of the average growth rate in uninfected animals is shown in blue. Co-infections of $T$. parva and $A$. marginale have a significant negative effect (synergistic) on ADWG, above the sum of their individual effects. Animals co-infected with T. parva and T. mutans have a significant positive interaction (antagonistic), with average growth rates in coinfected animals higher than in animals infected with $T$. parva only. The model controls for the non-infectious factors. $($ ns) $=$ non-significant effect.

were much lower compared with those observed in smallholder farms in parts of Central Kenya (240-290 $\mathrm{g} \mathrm{day}^{-1}$ ) mainly keeping improved breeds
(Gitau et al. 2001), some of the fastest growing animals in the current study gained more than $300 \mathrm{~g} \mathrm{day}^{-1}$. 
The smallholder farms in Central Kenya predominantly keep improved breeds as opposed to those in Western Kenya keeping zebus, but do not themselves meet the recommended $400-500 \mathrm{~g}$ day $^{-1}$ target growth rates for dairy farms (Gitau et al. 2001; Heinrichs and Radostits, 2001). If the finding that some indigenous zebu cattle are growing at rates higher than improved breeds in smallholder settings has a genetic basis, this points to possible opportunities for improved livestock production through within-breed selection. Although withinbreed is considered a slow method of genetic improvement when compared with selection between breeds or cross-breeding, it is more permanent and cumulative in areas of high disease pressures where other breeds easily succumb to disease (FAO, 2007).

While controlling for the important non-infectious factors, this study has identified gastrointestinal worm burden (strongyle epg count), presence of dermatophyte Trichophyton spp. and tick-borne disease $T$. parva with its co-infections with $T$. mutans and A. marginale to be the important infections associated with greatest negative impact on growth rates.

The impact of helminth infections was a burdendependent effect with an increase in strongyle epg count by 1000 eggs associated with a $3 \cdot 3 \%$ decrease in growth rate. Some study calves had high helminth burden reaching up to $12000 \mathrm{epg}$, which would translate to up to $30 \%$ loss in growth rate in heavily infected calves. By colonizing the gastrointestinal tract, helminth infections lead to inefficient feed utilization, and in cases such as infections with hookworms result in pathological lesions on gastrointestinal walls to which they attach. In this study the negative effects of individual worm infections (for example, infections with Haemonchus placei, Trichostrongylus axei and Oesophagostomum radiatum were all found to negatively affect growth) in the model are masked when strongyle egg counts are introduced as a variable, suggesting strongyle epg may be a good practical composite measure of worm burden in these calves.

Infection with the dermatophyte Trichophyton spp., although identified in only $7 \cdot 8 \%$ of the calves, was associated with a large decrease $(18.9 \%)$ in growth rate. Fungal infections will usually not cause clinical disease or be associated with weight loss but their effect is enhanced in immunosuppressed hosts, a good example being in humans with AIDS. This association is however yet to be confirmed in animals (Blanco and Garcia, 2008). The animals identified infected with Trichophyton spp. in this study were systemically affected and with stunted growth. It is likely the fungal infections here may be the result of poor health as opposed to being the cause, and the poor growth observed in infected animals may be related to other underlying conditions.
Regarding tick-borne diseases, seropositivity to T. parva, the protozoan parasite causing ECF disease, was associated with the greatest impact on growth; this was estimated as a $13.7 \%$ decrease in growth rate compared with $T$. parva seronegative animals. It has previously been reported that indigenous calves infected with $T$. parva had stunted growth even though they did not show any clinical disease (Moll et al. 1986). No other tick-borne infection had a significant effect on growth rate as single infections. However, the results suggest pathogen-pathogen interactions in individuals coinfected with $T$. parva and $A$. marginale. The growth rate in animals seropositive for $T$. parva and A. marginale had the average daily weight gain reduced by $23 \cdot 6 \%$, a percentage greater than sum of the effect of individual pathogens $(15 \cdot 3 \%)$, suggesting a synergistic interaction (harming the host more).

The processes by which interactions between T. parva and A. marginale occur are unclear and have not been fully investigated. McHardy and Kiara (1995) observed that about 50\% of clinical cases of $\mathrm{ECF}$ among improved breeds in Kiambu district, Kenya were complicated by $A$. marginale infections. Experimental studies from their work showed superinfection with $T$. parva resulted in a relapse of severe clinical anaplasmosis and severe anaemia even though A. marginale parasitaemia remained low. It may be possible that the effect observed is mediated through the immune system and related to an immunesuppression associated with the destruction of lymphocytes infected with T. parva. In the same study, McHardy and Kiara (1995) showed that calves superinfected with $T$. parva when the carrier state of Anaplasma had stabilized had mild anaplasmosis disease with a moderate fall in PCV suggesting that $\mathrm{ECF}$ may interfere with the immunity to anaplasmosis. Experimental studies looking at immunological changes accompanied by these different infection profiles may help improve understanding of the mechanisms by which $T$. parva and A. marginale may be interacting.

Unlike interactions with $A$. marginale, having a $T$. parva-T. mutans co-infection was identified to be advantageous on host growth rate. Animals that were ever seropositive for $T$. mutans had an estimated decrease in growth rate of $6 \cdot 7 \%$, which was less than half the sum of the estimated T. parva and T. mutans effects $(15 \cdot 3 \%)$, an antagonistic interaction. These data are based on serology results, and data based on presence or absence of parasites in blood, for example Reverse Line Blot across all time points would be useful to confirm results.

This result suggests the presence of T. mutans, considered a benign pathogen (Brocklesby et al. 1972; Coetzer and Tustin, 2004) may be reducing the negative impact on host growth rate by the more pathogenic T. parva infection. The mechanisms by which these two Theileria species may be interacting 
are unclear and may only be postulated. One possibility would be interactions through competition for cell resources, which would occur if the presence of $T$. mutans negatively affected $T$. parva parasite densities, thereby reducing the large impact $T$. parva has on host growth. Such competitive interactions between parasites modifying densities of competing parasites have been demonstrated in other studies (Lello et al. 2004; Conlan et al. 2009).

The second possible mechanism by which these parasites could interact is through the host immune system. This would happen if immune responses elicited following T. mutans infection offers some level of protection against subsequent $T$. parva infections. Currently, there is little evidence in immunology literature supporting this theory and to a large extent solid cross-protection against Theileria species is thought to work only among homologous parasites. Immunity against $T$. mutans remains largely unstudied, perhaps because T. mutans is normally benign and has attracted little interest among researchers. The protective immunity against T. parva is thought to occur in two ways: (a) humoral immunity against the sporozoites injected by infected ticks, and (b) cell-mediated immune responses against macroschizont-infected cells which are thought to express surface antigens that can be targeted by effector killer T-cells. Effects of humoral responses are thought to be limited mainly due to the thousands of sporozoites a single infected tick injects in a host, and the rapidity with which the sporozoites enter target lymphoid cells.

However, in vitro studies have demonstrated that antibodies against $T$. parva (Muguga strain) neutralized infectivity not just against homologous sporozoites but against other T. parva strains as well (Musoke et al. 1984). This finding is important even though it is still unclear how important these humoral responses are in reducing sporozoites infectivity in vivo, and whether the observed crossprotection between $T$. parva strains extend to other species such as T. mutans or vice versa. This would offer a possible explanation to the observed beneficial effects of a $T$. parva co-infection with $T$. mutans. Experimental work looking at the immune responses with different combinations of the infections with these two Theileria species may help improve our understanding of these interactions.

Different ticks transmit the two Theileria species: T. parva by Rhipicephalus appendiculatus and T. mutans by Amblyomma variegatum. These two ticks share large geographical overlaps in their distribution in East, Central and Southern Africa (Walker et al. 2003). This is supported by results of sero-surveillance studies done in different regions showing similar prevalence rates for both $T$. mutans and T. parva (Ogden et al. 2005; Swai et al. 2009; Gachohi et al. 2010). This widespread co-occurrence of the two Theileria species may indicate that although T. parva is still associated with huge losses in livestock, the effect may be moderated to an extent by co-occurrence with T. mutans.

The results obtained here identify simple farm management practices that would help improve the growth rates of zebu calves. Although it is not entirely clear how providing drinking water to the animals from within the homestead works, this simple husbandry practice is estimated to be associated with preventing an estimated $8 \cdot 6 \%$ reduction in growth rate compared with farms where animals walk a distance away from the homestead to access water. Secondly, since dam heart girth sizes were identified as good predictors for growth rate in calves, farmers or breeders can improve their decisionmaking in selecting animals to keep for breeding based on the relative dam sizes.

The two main infections, with high prevalences and strongly associated with decreased growth rate, are helminths and T. parva infections. Although animals are infected with many different species of worms, this study has identified strongyle epg count as a good composite measure quantifying the effect helminths have on the host. Data on strongyle epg are relatively easy and inexpensive to collect under field conditions. A herd's helminth burden can be estimated and a decision on helminth control made based on the results. Here, the results show helminth control would prevent the loss of growth rates estimated at up to $30 \%$ in animals heavily infected.

Tick control would be expected not only to reduce the direct effects exerted by feeding ticks [the tick $A$. variegatum has been associated with decreased growth rates (Stachurski et al. 1993)] but also on the impact of pathogens they transmit. Specifically, it would be expected the beneficial effect would be not just reducing impact of $T$. parva but of the more harmful $T$. parva-A. marginale co-infections. The finding of $T$. mutans reducing the impact of the more pathogenic $T$. parva in cases of coinfections with the two parasites may be a relationship that can be exploited to reduce impacts of $T$. parva infections. Such relationships have been used to control for Anaplasmosis where the more benign Anaplasma centrale has been used as a vaccine for the more pathogenic A. marginale (Kocan et al. 2010).

This information points to evidence that by reducing the prevalence of one pathogen, the benefit is likely greater beyond that estimated by just removing the effect of individual pathogens. There is a need to better understand the mechanisms by which $T$. parva interacts with $A$. marginale and with $T$. mutans, possibly through experimental work, as these provide opportunities for improved design of disease-control strategies and increased livestock production. 


\section{SUPPLEMENTARY MATERIAL}

To view supplementary material for this article, please visit http://dx.doi.org/10.1017/ S0031182013001261

\section{ACKNOWLEDGEMENTS}

This work was done as part of the Infectious Diseases of East African Livestock (IDEAL) project, a collaborative project between the University of Edinburgh, University of Pretoria, University of Nottingham and the International Livestock Research Institute (ILRI), Nairobi, Kenya. We would like to thank the Kenyan Department of Veterinary Services for their logistical support, participating farmers, and the animal health and laboratory technicians who participated in the running of the project. We are grateful to Olga Tosas-Auguet and Maia Lesosky for their contribution in the designing and management of the databases.

\section{FINANCIAL SUPPORT}

This work was supported by the Wellcome Trust (grant No. 079445).

\section{REFERENCES}

Blanco, J. L. and Garcia, M.E. (2008). Immune response to fungal infections. Veterinary Immunology and Immunopathology 125, 47-70.

Boag, B., Lello, J., Fenton, A., Tompkins, D. M. and Hudson, P. J. (2001). Patterns of parasite aggregation in the wild European rabbit (Oryctolagus cuniculus). International fournal for Parasitology 31, 14211428.

Brocklesby, D. W., Sellwood, S. A. and Harness, E. (1972). Some characteristics of a strain of Theileria mutans (Theiler, 1906) isolated from cattle in the county of Kent, England, and maintained in splenectomized calves. International Fournal for Parasitology 2, 265-271.

Bronsvoort, B. M. D. C., Thumbi, S., Poole, J., Kiara, H., TosasAuguet, O., Handel, I., Jennings, A., Conradie, I., Toye, P., Hanotte, O., Coetzer, K. and Woolhouse, M. E. J. (in press). Design and Descriptive epidemiology of the Infectious Diseases of East African Livestock (IDEAL) project, a longitudinal calf cohort study in western Kenya. BMC Veterinary Research.

Coetzer, J. and Tustin, R. (ed.) (2004). Infectious Diseases of Livestock, 2nd Edn. Oxford University Press, Oxford, UK.

Conlan, J.V., Vongxay, K., Fenwick, S., Blacksell, S.D. and Thompson, R.C.A. (2009). Does interspecific competition have a moderating effect on Taenia solium transmission dynamics in Southeast Asia? Trends in Parasitology 25, 398-403.

Cox, F. E. (2001). Concomitant infections, parasites and immune responses. Parasitology 122 (Suppl), S23-S38.

Craig, B. H., Tempest, L. J., Pilkington, J. G. and Pemberton, J. M. (2008). Metazoan-protozoan parasite co-infections and host body weight in St Kilda Soay sheep. Parasitology 135, 433-441.

Diggle, P. J., Heagerty, P. J., Liang, K. Y. and Zeger, S. L. (2003). Analysis of Longitudinal Data. Oxford University Press, Oxford, UK.

Food and Agriculture Organization (FAO). (2007). The State of the World's Animal Genetic Resources for Food and Agriculture (ed. Rischkowsky, B. and Pilling, D.). FAO, Rome, Italy.

Fenton, A. and Perkins, S. E. (2010). Applying predator-prey theory to modelling immune-mediated, within-host interspecific parasite interactions. Parasitology 137, 1027-1038.

Gachohi, J. M., Ngumi, P. N., Kitala, P. M. and Skilton, R. A. (2010). Estimating seroprevalence and variation to four tick-borne infections and determination of associated risk factors in cattle under traditional mixed farming system in Mbeere District, Kenya. Preventive Veterinary Medicine 95, 208-223.

Gitau, G. K., Mcdermott, J. J., McDermott, B. and Perry, B. D. (2001). The impact of Theileria parva infections and other factors on calf mean daily weight gains in smallholder dairy farms in Murang'a District, Kenya. Preventive Veterinary Medicine 51, 149-160.

Graham, A. L. (2008). Ecological rules governing helminth-microparasite coinfection. Proceedings of the National Academy of Sciences USA 105, 566-570.
Gröhn, Y.T., Mcdermott, J. J., Schukken, Y. H., Hertl, J. A. and Eicker, S.W. (1999). Analysis of correlated continuous repeated observations: modelling the effect of ketosis on milk yield in dairy cows. Preventive Veterinary Medicine 39, 137-153.

Hansen, J. and Perry, B. (1994). The Epidemiology, Diagnosis and Control of Helminth Parasites of Ruminants, A Handbook, 2nd Edn. ILRAD, Nairobi, Kenya.

Heinrichs, A. and Radostits, O. (2001). Health and production management of dairy calves and replacement heifers. In Herd Health, Food Animal Production Medicine, 3rd Edn (ed. Radostits, O.), pp. 333-395. W.B. Saunders, Philadelphia, PA, USA.

Katende, J., Morzaria, S., Toye, P., Skilton, R., Nene, V., Nkonge, C. and Musoke, A. (1998). An enzyme-linked immunosorbent assay for detection of Theileria parva antibodies in cattle using a recombinant polymorphic immunodominant molecule. Parasitology Research 84, 408-416.

Kocan, K. M., De La Fuente, J., Blouin, E.F., Coetzee, J.F. and Ewing, S. A. (2010). The natural history of Anaplasma marginale. Veterinary Parasitology 167, 95-107.

Kristjanson, P., Krishna, A., Radeny, M. and Nindo, W. (2004). Pathways out of Poverty in Western Kenya and the Role of Livestock. FAO, Rome, Italy.

Lafferty, K. D. (2010). Microbiology. Interacting parasites. Science (New York, NY) 330, 187-188.

Latif, A., Rowlands, G. and Punyua, D. (1995). An epidemiological study of tick-borne diseases and their effects on productivity of zebu cattle under traditional management on Rusinga Island, western Kenya. Preventive Veterinary Medicine 22, 169-181. Elsevier, Amsterdam, the Netherlands.

Lello, J. and Hussell, T. (2008). Functional group/guild modelling of inter-specific pathogen interactions: a potential tool for predicting the consequences of co-infection. Parasitology 135, 825-839.

Lello, J., Boag, B., Fenton, A., Stevenson, I. R. and Hudson, P. J. (2004). Competition and mutualism among the gut helminths of a mammalian host. Nature 428, 840-844.

McHardy, N. and Kiara, H. (1995). Super-infection with Theileria parva in calves previously infected with Babesia bigemina or Anaplasma marginale. In International Conference on Tick-borne Pathogens, Kruger National Park (South Africa), 28 August-1 September 1995.

Moll, G., Lohding, A., Young, A. S. and Leitch, B. L. (1986). Epidemiology of theileriosis in calves in an endemic area of Kenya. Veterinary Parasitology 19, 255-273. Elsevier, Amsterdam, the Netherlands.

Morzaria, S. P., Katende, J., Musoke, A., Nene, V., Skilton, R. and Bishop, R. (1999). Development of sero-diagnostic and molecular tools for the control of important tick-borne pathogens of cattle in Africa. Parassitologia 41(Suppl 1), 73-80.

Murray, M., Murray, P. K. and Mcintyre, W. I. (1977). An improved parasitological technique for the diagnosis of African trypanosomiasis. Transactions of the Royal Society of Tropical Medicine and Hygiene 71, 325-326.

Musoke, A., Nantulya, V. and Rurangirwa, F. (1984). Evidence for a common protective antigenic determinant on sporozoites of several Theileria parva strains. Immunology 52, 231-238.

Ndungu, S. G., Ngumi, P. N., Mbogo, S. K., Dolan, T. T., Mutugi, J. J. and Young, A. S. (2005). Some preliminary observations on the susceptibility and resistance of different cattle breeds to Theileria parva infection. Onderstepoort Fournal of Veterinary Research 72, 7-11

Ogden, N.H., Swai, E., Beauchamp, G., Karimuribo, E., Fitzpatrick, J.L., Bryant, M. J., Kambarage, D. and French, N.P. (2005). Risk factors for tick attachment to smallholder dairy cattle in Tanzania. Preventive Veterinary Medicine 67, 157-170.

OIE. (2008). Manual of diagnostic tests And vaccines For terrestrial animals, 6th Edn., p. 1343. Office International des Epizooties, Paris, France.

Pedersen, A. B. and Fenton, A. (2007). Emphasizing the ecology in parasite community ecology. Trends in Ecology and Evolution 22, 133-139.

Perry, B. (2002). Investing in Animal Health Research to Alleviate Poverty. International Livestock Research Institute, Nairobi, Kenya.

Perry, B. (2007). Poverty reduction through animal health. Science (USA) 315, 333-334.

Pinheiro, J. and Bates, D. (2000). Mixed Effects Models in S and S-Plus. Springer-Verlag, NewYork.

R Development Core Team (2011). R: A Language and Environment for Statistical Computing. R Foundation for Statistical Computing, Vienna, Austria. ISBN 3900051070 URL http://www.R-project.org.

Stachurski, F., Musonge, E. N., Achu-Kwi, M. D. and Saliki, J. T. (1993). Impact of natural infestation of Amblyomma variegatum on the 
liveweight gain of male Gudali cattle in Adamawa (Cameroon). Veterinary Parasitology 49, 299-311.

Swai, E. S., Karimuribo, E.D., Kambarage, D. M. and Moshy, W.E. (2009). A longitudinal study on morbidity and mortality in youngstock smallholder dairy cattle with special reference to tick borne infections in Tanga region, Tanzania. Veterinary Parasitology 160 34-42.

Tarawali, S., Herrero, M., Descheemaeker, K., Grings, E and Blümmel, M. (2011). Pathways for sustainable development of mixed crop livestock systems: taking a livestock and pro-poor approach Livestock Science 139, 11-21.

Tebele, N., Skilton, R.A., Katende, J., Wells, C. W., Nene, V., Mcelwain, T., Morzaria, S. P. and Musoke, A. J. (2000). Cloning, characterization, and expression of a 200-kilodalton diagnostic antigen of Babesia bigemina. Fournal of Cinical Microbiology 38, 2240-2247.

Telfer, S., Lambin, X., Birtles, R., Beldomenico, P., Burthe, S., Paterson, S. and Begon, M. (2010). Species interactions in a parasite community drive infection risk in a wildlife population. Science (New York, N.Y.) 330, 243-246.

Tomley, F. M. and Shirley, M. W. (2009). Livestock infectious diseases and zoonoses. Philosophical Transactions of the Royal Society of London 364, 2637-2642.

Walker, A., Bouattour, A., Camicas, L., Estrada-Pena, A., Horak, I. Latif, A., Pegram, R. and Preston, P. (2003). Ticks of Domestic Animals in Africa: a Guide to Identification of Species. Bioscience Reports, Edinburgh, UK. Weir, J.P. (2005). Quantifying test-retest reliability using the intraclass correlation coefficient and the SEM. Fournal of Strength and Conditioning Research 19, 231-240.

Willett, J. (1997). Measuring change: what individual growth modeling buys you. In Change and Development: Issues of Theory, Method and Application (ed. Amsel, E. and Renninger, K. A.), pp. 213-243. Lawrence Erlbaum Associates, Mahwah, NJ, USA.

Woo, P. T. (1970). The haematocrit centrifuge technique for the diagnosis of African trypanosomiasis. Acta Tropica 27, 384-386. 